\title{
Geographical Structures and Urban-Rural Settlements: A Design for the Sarno River and its Plain
}

\author{
REJANA LUCCI \\ Professor, Dipartimento di Architettura DiARC, Università di Napoli Federico II, \\ Roma, Italy
}

\section{Email: rejlucci@fastwebnet.it}

Received: May 8th, 2014 | Revised: January 10th, 2015 | Accepted: January 12th 2015

Published online: January 21, 2015

The Author(s) 2015. This article is published with open access at www.chitkara.edu.in/publications

\begin{abstract}
The research presented in this paper deals with the theme of the reclamation of a territory which, though rich in memories of the past and in important traces of its country's and settlement's culture, is today largely degraded. The study area - in South Italy, Naples District - is the plain of the Sarno River. It lies on the south of Mount Vesuvius, between the slopes of the volcano, the Picentini mountains and the sea coast, with the river as central axis. It is simply an area full of historical memories: Pompei stood there with its harbour on the river, Stabiae and Nuceria, and there are the remains of several centuries that left marks on which the territory was built. Since ancient times it has been crossed by major communication routes between north and south. The Sarno River, with its central axis and an extensive network of tributaries and canals, was the principal resource of the area. Due to the abundance of water and the rich volcanic soil, it has always been a land of specialized crops and of manufacturing production. Even today it is an important agricultural area, and a landscape of interest. But, by now, the Sarno River Plain, especially towards the sea, is a territory invaded by uncontrolled urbanization, with high-density zones of poor-quality buildings, which have some cities between them. This carelessness has made the river the first cause of the ecological disaster of this area (with waste, industrial and food poisons): a situation of a typical urban territory sprawled and polluted.

We think that an important design issue here is thinking of the Sarno River as the soul of the region, the powerful element that still can restore the lost identity of the area, so that after the rehabilitation has already begun - it will be possible to redevelop the relationships between urban areas, rebuild their hierarchies, and restore the character of agricultural areas and the existing characteristic nature, by protecting and enhancing them.
\end{abstract}

Keywords: Urban design, geography, infrastructures, urban-rural settlements, collective centers

\section{INTRODUCTION}

The architectural issues addressed in this study mainly relate to the theme of the existing relationships between the territory's geographical structure and the urban settlements and arrangement of human activities. From this relationship, we think, it is possible today to start processes of reclamation and transformation of deteriorated areas.
Creative Space Vol. 2, No. 2, January 2015 pp. 241-253

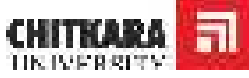

C2015 by Chitkara University. All Rights Reserved. 
The history of the human land occupation has always been linked, as it is well known, to the criteria of selection of the most suitable places for different activities, of practical choices for a good life, safety, health, productivity. These criteria then become rules, measures and settlement's forms with ritual, canonical, symbolic characters, all closely related to the different cultures and eras. We just think of the recurring elements of foundation of the Hippodamian city (Coppa, 1968), or the sulcus primigenium in old Italic settlements, or the centuriatio of territories in Roman times (Bussi, 1984), when the practical needs of the division and allocation of the fields is matched by a whole world of measures (the actus, the iugerum, the heredium, the centuria), of guidelines, of hierarchies that have become persistent signs of a settlement culture. But they have also become the particular characteristics of entire areas of the Italian territory, recognizable landscapes. Fields, roads, urban settlements and, canalizations systems are all signs around which the transformation of those territories has been carried out. And today, they could still be the structure around which to rebuild a persisting character and a recognizable identity.

Already in Vitruvius, the choice of places for condere urbem or coloniam deducere was linked to health and fertility. Or, in the pages of Alberti, we find information on "the shape of the decent and charming place; never lower sunk, but rather high above the surrounding area, and that can be continually cheered up by a good air." Even in the modern era, considering the problem of devising the new post-industrial city, Ludwig Hilberseimer (1949) designed a precise, limited-size settlement unit, which would be distributed in an extensive and regular way on the territory. He divided them into different functions, arranged in a non-confrontational way, careful of solar exposure and winds. In addition, he tested the feasibility and adaptability of these schemes right through their inclusion in geographically and topographically different places: along a river, on a hill or, in rural areas of varying nature. Also, the geographic features determine the adaptation and variation processes related to that specific place. He thus reached a definition of an urban-rural planning system, in which industry and agriculture were re-tuned with the human settlements, as a new model of modern urbanisation that had a regional character.

Starting instead from a reading of architecture and design of a well-defined Italian geographical territory (Abruzzo), Agostino Renna (1980) detects a character that he still calls "urban-rural" in which "the emerging feature ... relating to the use and the occupation of the soil, to the precise demarcation of the place, to the very small amount of buildings compared to the entire area is that both the buildings and the unbuilt land assume the same role and dignity in the overall composition ... the possibility of an urban shape, including the countryside as its permanent member, emerges from this research." The 
countryside, with the activities that take place there, is understood as an element of the construction of the morphology of this particular form of non-compact city. Not only the relationship with nature and the topography directs, modifies and conditions the human intervention, the urban forms and the architecture, but the same structure of the territory, the elements that are present, their reciprocal arrangements define the character and the shape of the areas. What I mean is that the morphological structure of a continued territory, arisen from the defined relationships between the present elements (the river with its plain, with the mountains ... linked to that specific location), is the matrix of identity and recognisability. And, unfortunately, those are the critical characteristics that the current scattered or cumulated urban and territorial transformations tend to forget and cover with indifferent plots.

With this setting, the study is aimed at the reading of the Sarno plain, a territory between Naples, Vesuvius and Salerno, a clear geographic structure, rich in resources, full of memories and signs. But today it is affected by large deeds of scatter and land consumption, with linked settlements, and a high level of environmental pollution.

Even in the existing urbanised areas, which are as difficult to read and to understand as the Sarno plain, it continues to seem inevitable to devise a reading methodology to highlight, to describe and to make a list of their basic elements. As always, it's important for us to try to identify what is really a part of the building of the city, or of the building of the territory, whatever be the nature of the described area. Therefore, even in the case of the contemporary problematic areas, the aim is always to think that "the so-called chaos is quite a still not understood order" (Corboz, 1998), to know and investigate its components, to "find places in the chaos" of the urban territories, "to give them a name, and to develop their peculiarities. It's therefore an art of urban discovery and not of invention" (Ungers, 1997). Today we must understand which aspects of these complex urban territories (and compromises) are the real components of their structure and the potential development points for the transformation, and which ones are to overcome and abandon, avoiding to raise the "degradation" in an aesthetic category.

So it's necessary to describe, select and put back together the area's interesting data with a different logic, with the same attention to everything: from the special characters, with the memories that each past filed and transformed into meaningful marks, up to the current emerging issues that these areas show us. We want to re-put them together, to give other possible readings of the elements, and to form, with the design interpretation, interesting new and varied relationships between things. This one, with appropriate and realistic (for feasibility and use) visions of the future (needs), will let us imagine a more
Geographical

Structures and

Urban-Rural

Settlements: A

Design for the

Sarno River and its

Plain

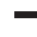


Lucci, R.

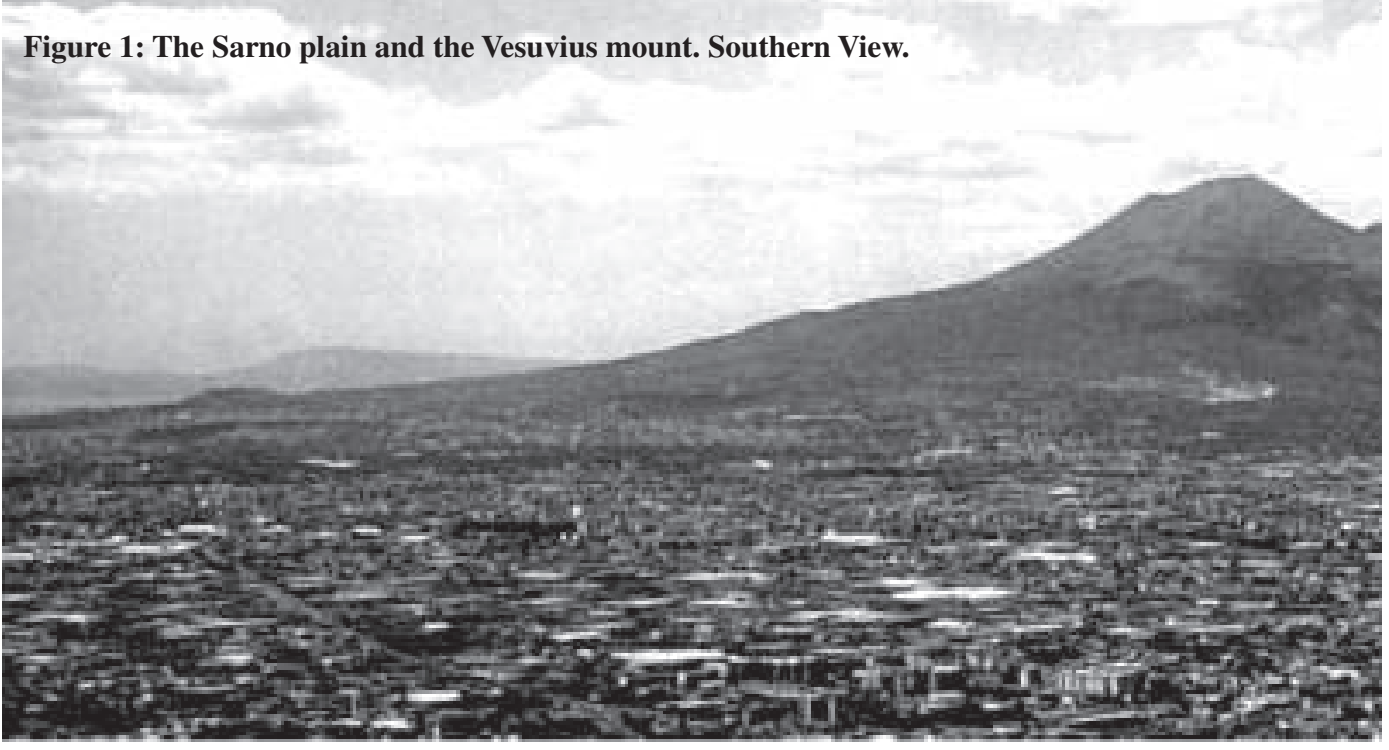

beautiful and livable territory (Gregotti, 2008 and De Solà Morales, 1999). The characters of the reading of urban areas, as we have done it, have a designing and an interpretative valence. This complex and layered reading will allow us to identify inherent issues in the different areas, where the generality of the chosen theme joins itself to its precise delimitation and to the peculiar needs related to the place's individuality. (De Matteis, 1996).

This reading then has identified the overall Sarno plain as a city-countryside: a spread out polycentric urban-rural city, consisting of small urban centers, from a tiny network of local roads that follow the trends and divisions of the fields, and finally, from an extended part of productive countryside. The theme of the project, identified to conduct the plain to its regeneration as a unified and eco-sustainable settlement system, has addressed the issue of the relationship between natural infrastructure of the territory and the public places of the city and the countryside, which are understood as a system oriented to the overall reconstruction of the area.

\section{THE CONTEXT}

The study area is the Sarno river plain - near Naples, South Italy - extending to the south of Vesuvius Mount, between the slopes of the volcano, the slopes of the Picentini and Lattari mountains and the sea coast between Torre Annunziata-Pompei and Castellammare, with the river as central axis (Fig. 1). 


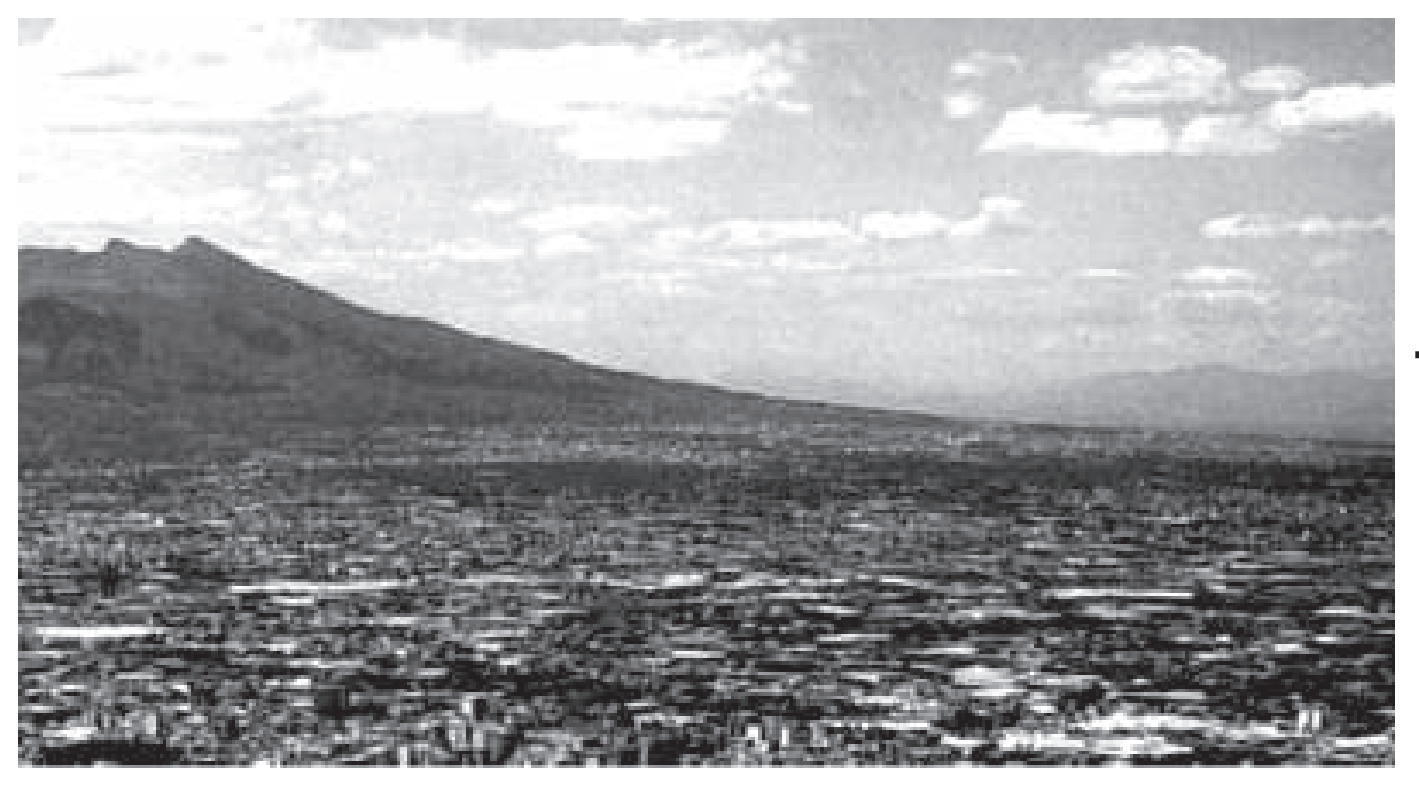

Geographical

Structures and

Urban-Rural

Settlements: A

Design for the

Sarno River and its

Plain

It is an area full of important historical traces: Pompei city stood there with its harbour on the river, Stabia, Nuceria, and, there are also some remains of three different centuriatio (Choquer, 1987).

The types urban settlement found here are of different nature and they have different roles and locations. Also, due to the particular nature of the alluvial soil, each one chose a place that would give security against the river's floods. Thus, there are two towns on the coast, at the two limits of the area (Torre Annunziata and Castellammare). Then, there are the piedmont settlements, standing in upper areas not subject to flooding, as Sarno and Nocera, and, those built on small hills in the valley, with the typical circular pattern, such as San Marzano, San Valentino and Striano.

Almost in the center of the plain, there is the town of Scafati, real crux of the area, born at the crossroads of two major existing infrastructures: the ancient Puteoli-Nuceriam road and the Sarno river. Even today the whole plain continues to have a very rich volcanic soil with a dense network of waterways, and, this is why it has always been a place of special crops and manufacturing production - a rich and beautiful countryside dotted with farms and isolated individual buildings, with the typical shape of a cube with vaulted ceilings (Musi, 2003).

Today, especially at the lower strip towards the sea, the plain is a territory invaded by uncontrolled urbanization, with high density areas of poor quality 


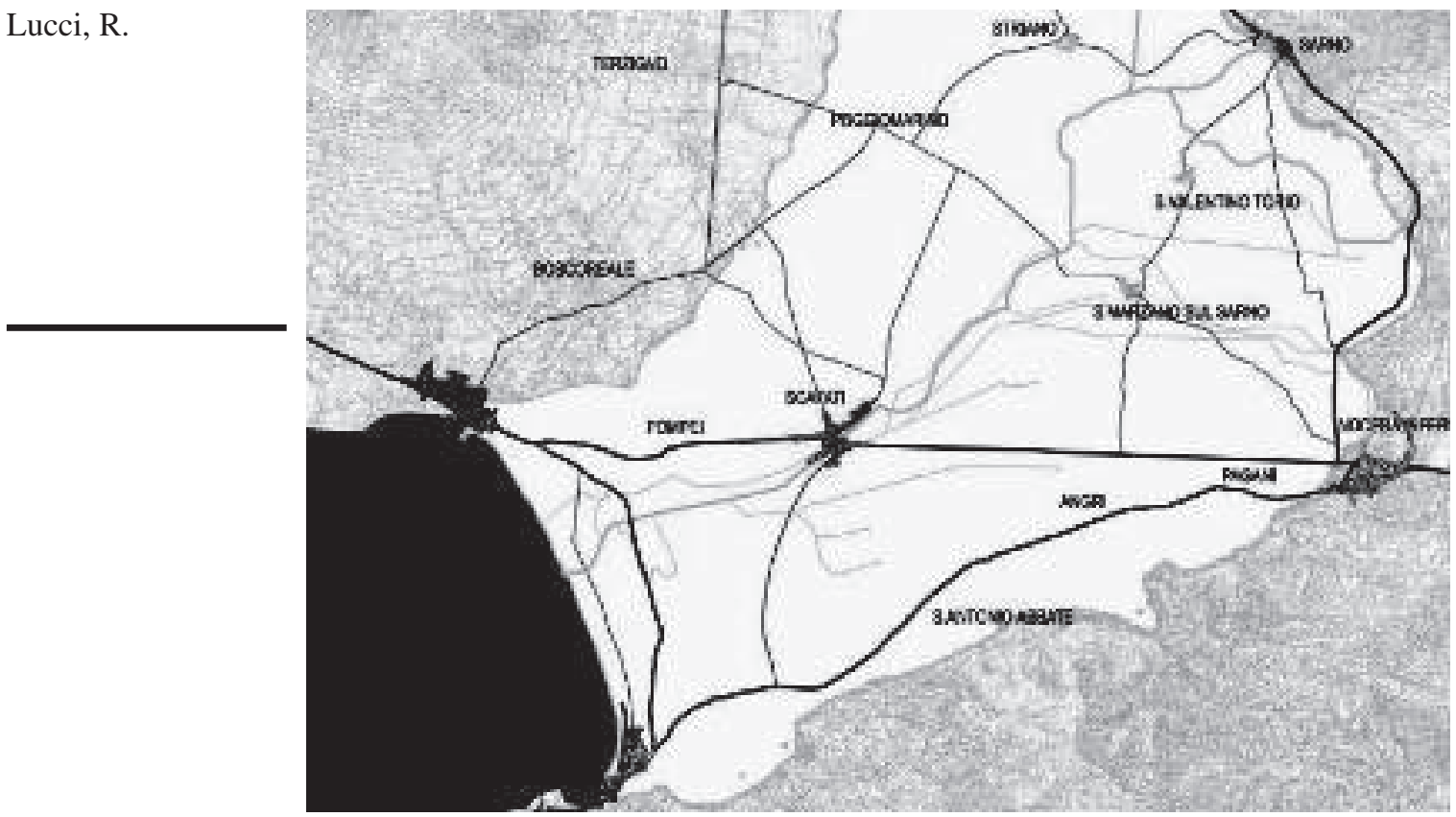

Figure 2: The original structure of the Sarno Plain.

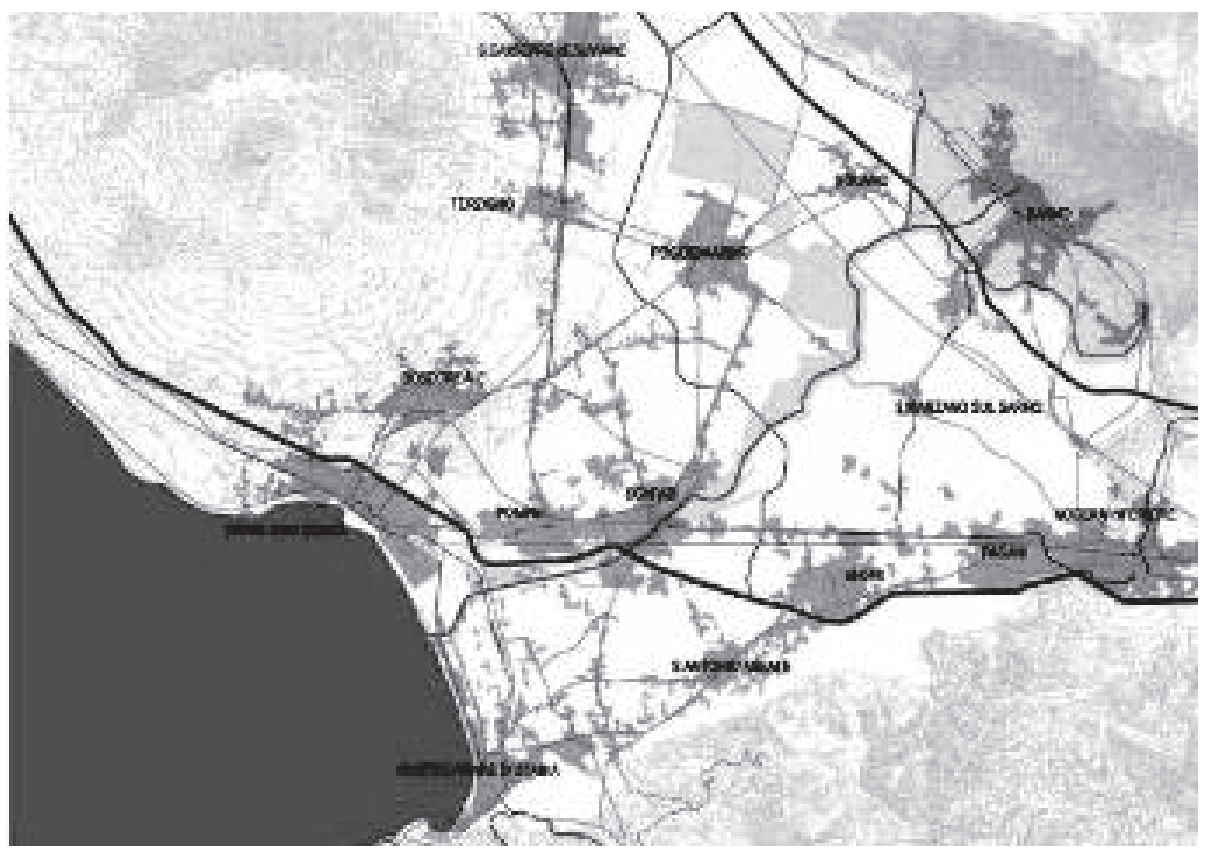

Figure 3: The Sarno Plain today. 
housing that have welded together some urban centers (Torre AnnunziataPompei-Scafati-Angri-Pagani-Nocera) and have obliterated all distinctions between urban and agricultural territory. There are tiny areas of building, often abusive, widely scattered, and a significant presence of plastic greenhouses covering the agricultural soil.

Since ancient times, the area was crossed by two main routes between north and south: the Puteoli-Nuceriam road - then road of Calabria, now 18 SS on the coast side - and the Popilia, at the foot of the Picentini mountains, from Nola, on the other side of Vesuvius Mount. At the present time, these well- established roads have been placed side by side, with a similar direction, by the A3 Napoli-Salerno-Reggio Calabria motorway, and the upper section of the A30 (Fig. 2).

However, the plot of the minor roads, until today, has remained a minute and irregular network, not organizing the scattered settlements. The roads do not join two defined points of the plane, but they follow, surround and accompany the shape of the fields. This further aggravates the feeling of disorientation perceived through the entire area. The Vesuvius remains the only strong element of orientation. Lately, the fully elevated SS 268 Vesuvius Road, running in north-south direction, was added to the two highways transversely crossing the flat, in order to improve the possible evacuation of the area for eruptive and seismic reasons.

There is also an extensive network of state, regional and local railways, starting with the first and most famous coastal railway line NaplesCastellammare (1840), with the bridge over the Sarno river. The last addition, on the other side, is the current extension of the high-speed line to Salerno. All these lines are uncritically superimposed on the territory with their own technical layout, and still today they are not organically connected to each other (Fig. 3).

\section{THE DESIGN}

The Sarno plain is currently an area where carelessness turned the river, once so important in the local identity to be identified with the deity of the place (Pesce, Milone, 2006), into the component responsible for the ecological disaster of the area, with the discharge of waste, industrial and food poisons, and with the lack of maintenance and upgrading of plumbing necessary for the proper flow of the water. Therefore, now it is a typical contemporary urban territory, dominated by housing densification and sprawl, by an extensive network of various infrastructures and by a significant pollution. But, though much impaired, the area still shows a possible unified structure.
Geographical

Structures and

Urban-Rural

Settlements: A

Design for the

Sarno River and its

Plain

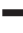



that we can name city-country because of the structure and the relationships among its components (the close relationship between morphological structure of urban settlements and the agricultural land, and the widespread presence of type of houses linked to production), and finally, because of the agricultural vocation, preserved in a large part of the area.

Altogether, it is evident that the current lack of clear "urban" relationships between the various settlements, namely the lack of a balance and a mutual role of "necessity" between the elements of the set, and of a hierarchy between parts. Each town has expanded (with different dimensions) according to its own way, in an individual manner through the existing planning instruments. The expected growth and the public facilities are designed with a limited overview of the relationship between the municipalities and the plain. Each administration autonomously develops, "in solitude", the plans for their own municipal territory, and the whole plain is further divided between the provinces of Naples and Salerno.

Whereas the current PTCP (Territorial Coordination Plan of the Naples Province, adopted in 2009 with programming 2009-2014) argues that "the analysis of the identity's components allows an allocation of the provincial system in meaningful areas related to the recurrence, the unity and homogeneity of the environmental and cultural roots". It suggests a vision for overcommunal homogeneous areas to perform a strengthening of "environmental infrastructures", a conservation of biodiversity and of landscape identity. With a similar perspective, the reading design led us to believe that the river Sarno can be the soul, the fundamental element that still can restore the lost identity of the entire area. This premise will make it possible to reconstruct the relationships between the existing disparate urban areas, giving them a clear hierarchy and restoring the typical character to the agricultural areas and the nature, by protecting and enhancing it, and even, with a reconstruction of the historical plots of rural landscapes.

The axis of the river thus becomes the place along which one can locate a unique crossing way and the major public places for the settlement's overall structure of the valley, the city-country, a location for placing over-communal facilities enhancing the identifying characteristics of the territory (Fig. 4).

The design mainly identifies the way to "slowly" cross the plain with a new road (all running on the ground, with bike path, pedestrian walkways and parking areas, the thick line in the figure) substantially parallel to the course of the river, recovering existing paths and local roads as much as possible. The new road starts from the current Ripuaria road at the mouth of the river and continues until it reaches the town of Sarno at the foot of the Picentini 


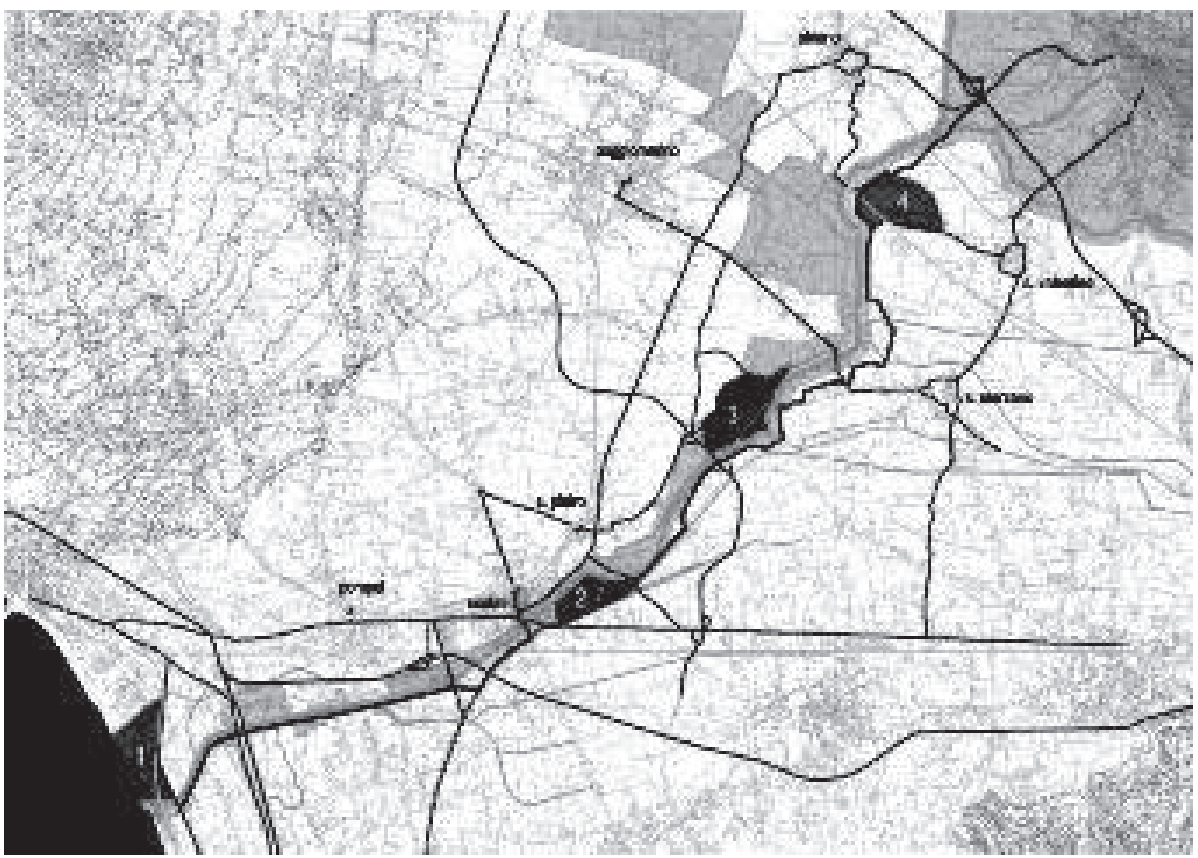

Geographical

Structures and

Urban-Rural

Settlements: A

Design for the

Sarno River and its

Plain

Figure 4: The Design of the Plain.

mountains. So it reconnects the coast and the mountains - the two limits of the plain - with a clear sign of orientation and crossing that allows a continuous relationship with the river, now lost, and systematizes the plot of the minor roads.

The new road is conceived as the backbone, as a long central spine along which are arranged the new collective places: along its route there are so located a series of collective territorial centers, linked to the particularities of the zones. Different activities are here condensed here, related to values of elements present (archeology, nature, agriculture, tourism), to become the main attractive characteristics for the whole area. These places are connected in an organic way with all existing infrastructure (roads and railway). These are located in different areas of special nature, according to the strategic role of the various zones in relation to the morphology of the valley, whether it is the mouth of the river and the coast; the central area of Scafati; the agricultural areas and the landscape on the point of confluence of several river branches and canals; and those areas related to small towns originating in the upper part of the valley, close to the new archaeological discoveries. 


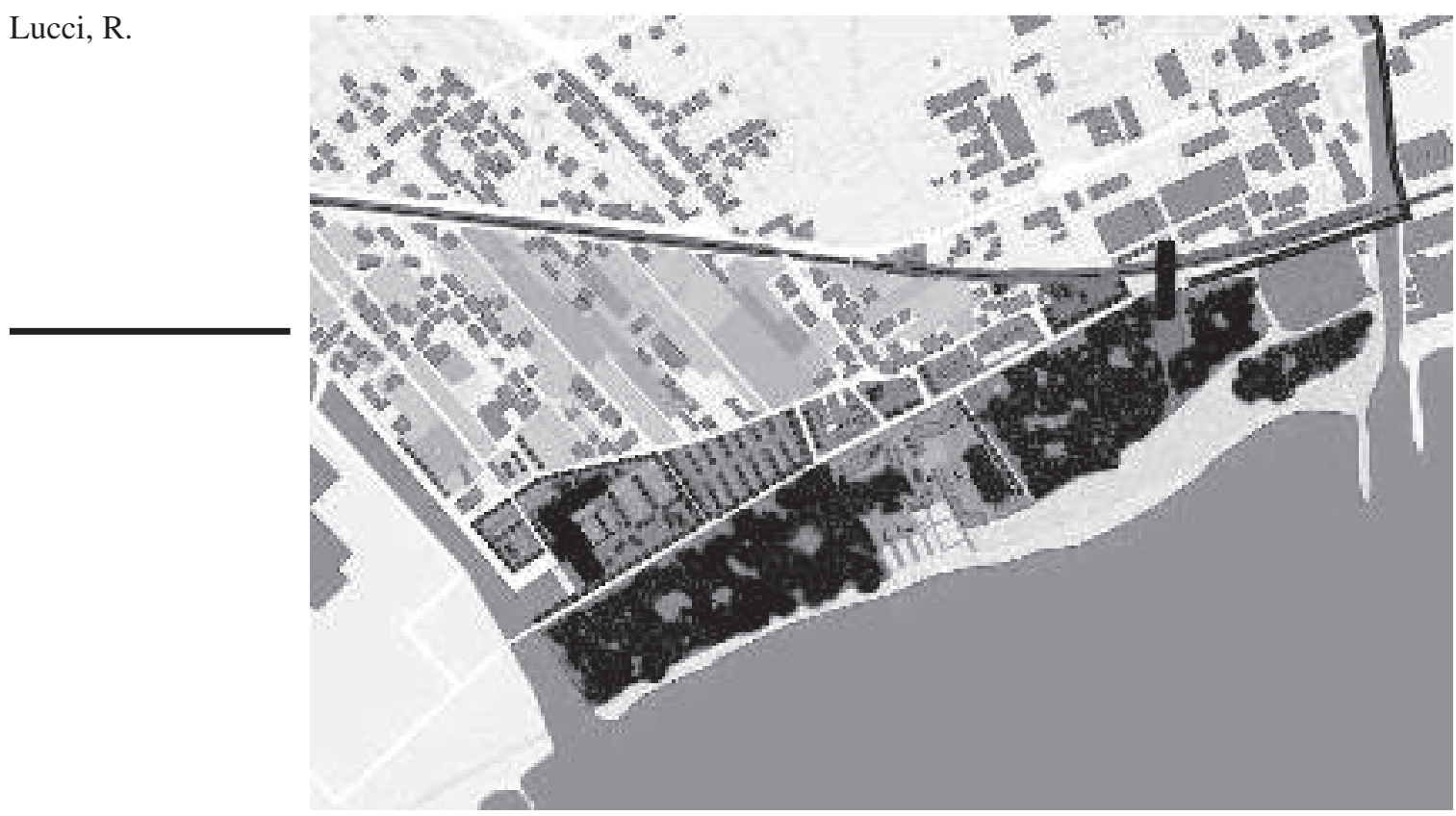

Figure 5: 1. The Mouth.

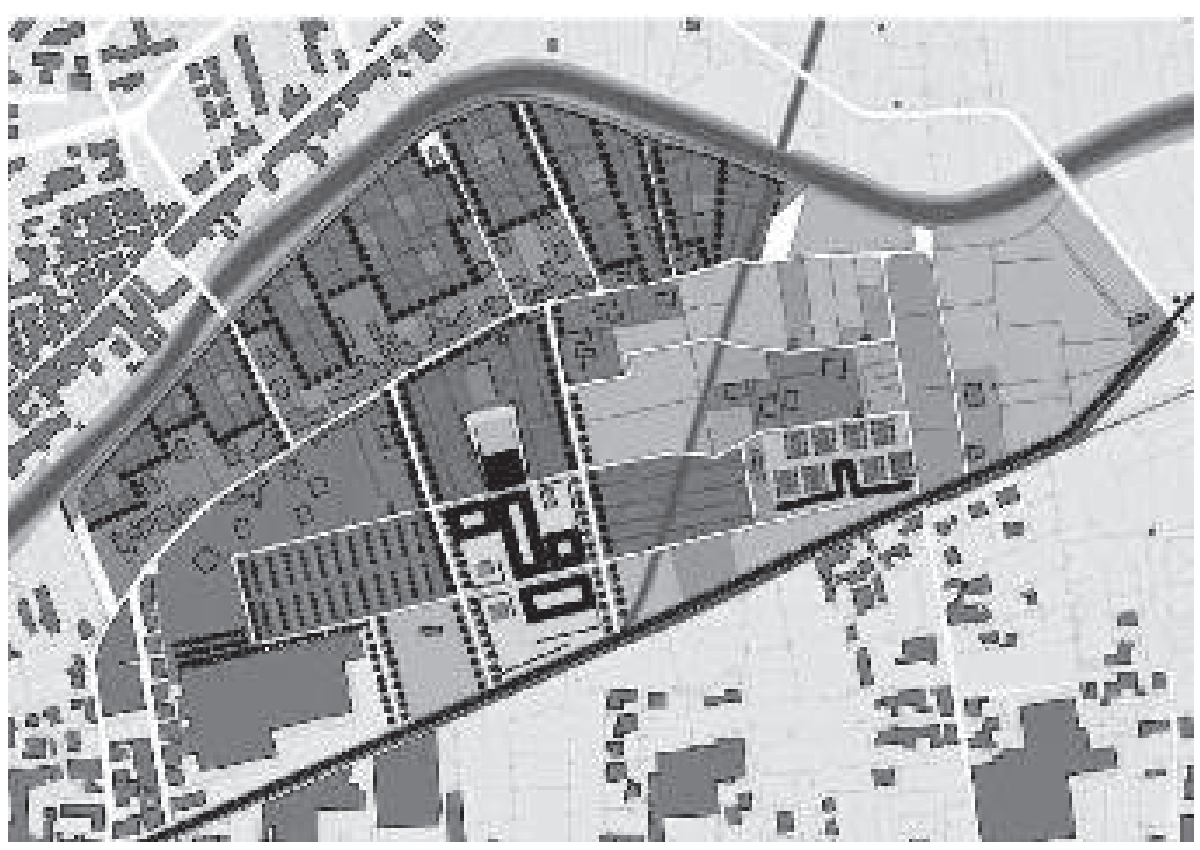

Figure 6: 2 . The Center. 
The prescribing principle of the settlements, characterizing all areas, is to consider them as centers of the urban-rural city. Collective activities are realized here in low-density buildings with character appropriate to the existing urban and rural typology. The predominance is given to green areas, some with facilities, part of reforestation, but largely the agriculture is still left. Always everything is in close relationship with the river, and with the new road.

\section{THE COLLECTIVE TERRITORIAL CENTERS}

In the area of 'The Mouth' the design theme is the reconquest of the relationship between the river and the sea, which was lost due to the locating industrial and manufacturing sectors in this coastal area. Between the current mouth and the new canal (that will be the second mouth) would be created a tourist accommodation and spa, with a building structure that refers to the courtyard type. There is also a landing on the new canal and a restored beach. There is a provision for a new regional railway station (now there is no intermediate stops between Torre Annunziata and Castellammare), and a railway bridge-station reconnecting parts of the territory now cut off from the sea by the tracks. And finally, between the two mouths, would be located a park with facilities, linked with the city of Torre Annunziata in an urban waterfront, along the beach for bathing use (Fig. 5).

In the area named 'The Center', in Scafati, we want to morphologically consolidate the central structure of the city for the entire plain. Like the Sarno city, at north, Scafati is the only urban center where the structure of the river had a strong presence and had entered in the definition of its character. In fact, the city was founded around the bridge Sarni on Urbulana road from Pompei, and its name originates from "scafa", an old ferry-boat's type. The oldest central district, the Mulini, is born just from the milling activity developed in the sixteenth century. And here was made a dam and the Bottaro canal opened to improve the flow of the river. Just beyond this central area, in a bend of the river even in urban areas, is located the second collective center of the plain, a point to start knowing the area, and also an improvement of equipment for the city. Here would be located a great info-point (either on news on the riverside park or on the whole area of the Sarno plain and on its vicinity). It consists of a wall's enclosure fabric, with fences and courts, related to the texture of the ancient urban fabric, and directly accessible from the new cross roads. Towards the river shore lies an urban park, with facilities for rest and sports (tennis, gymnastic routes, little athletics), and with recreational facilities (outdoor theater and cinema ...), and a nature trail on the river, complete with
Geographical

Structures and

Urban-Rural

Settlements: A

Design for the

Sarno River and its

Plain 


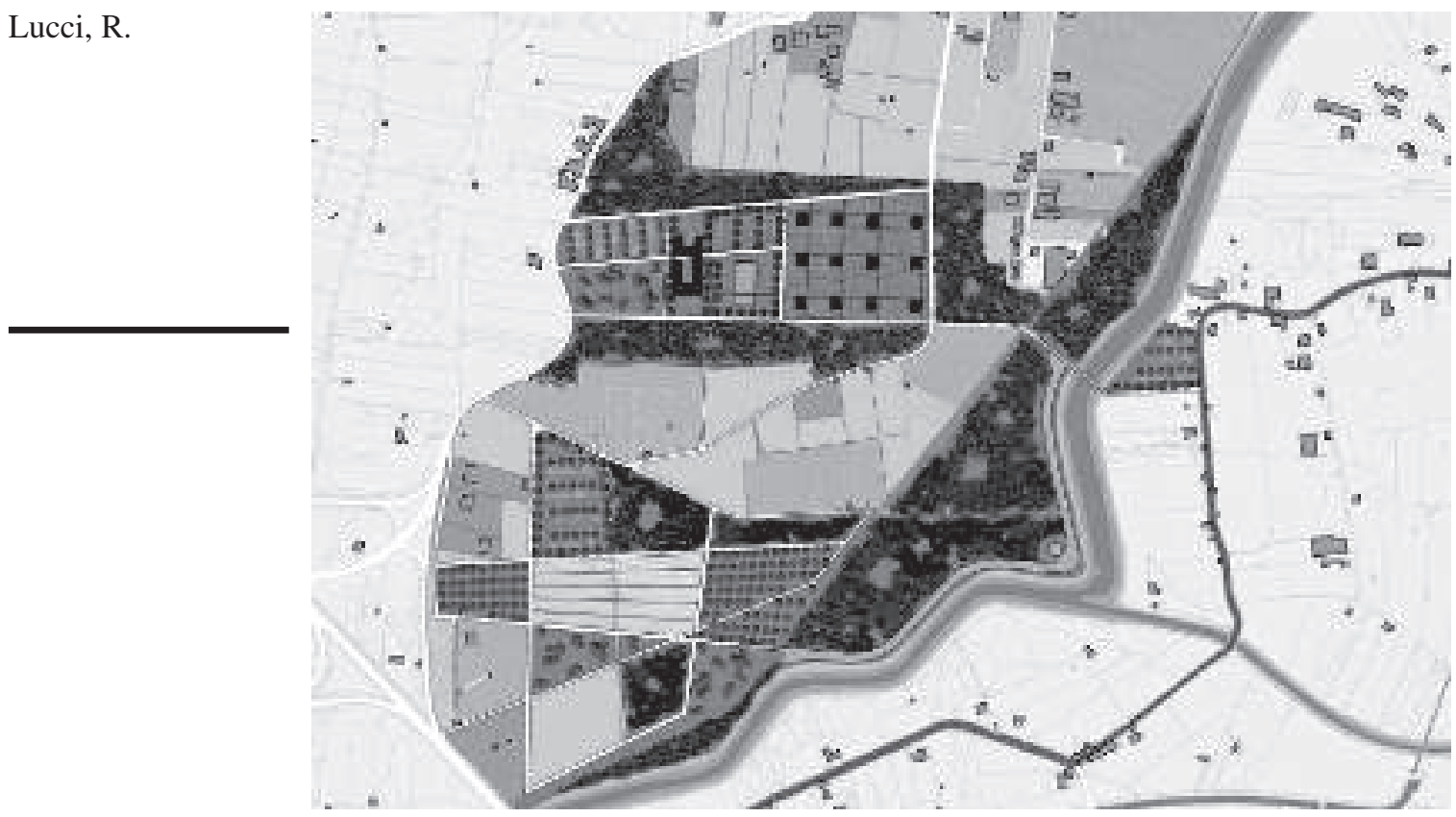

Figure 7: 3 . The Knot of Water.

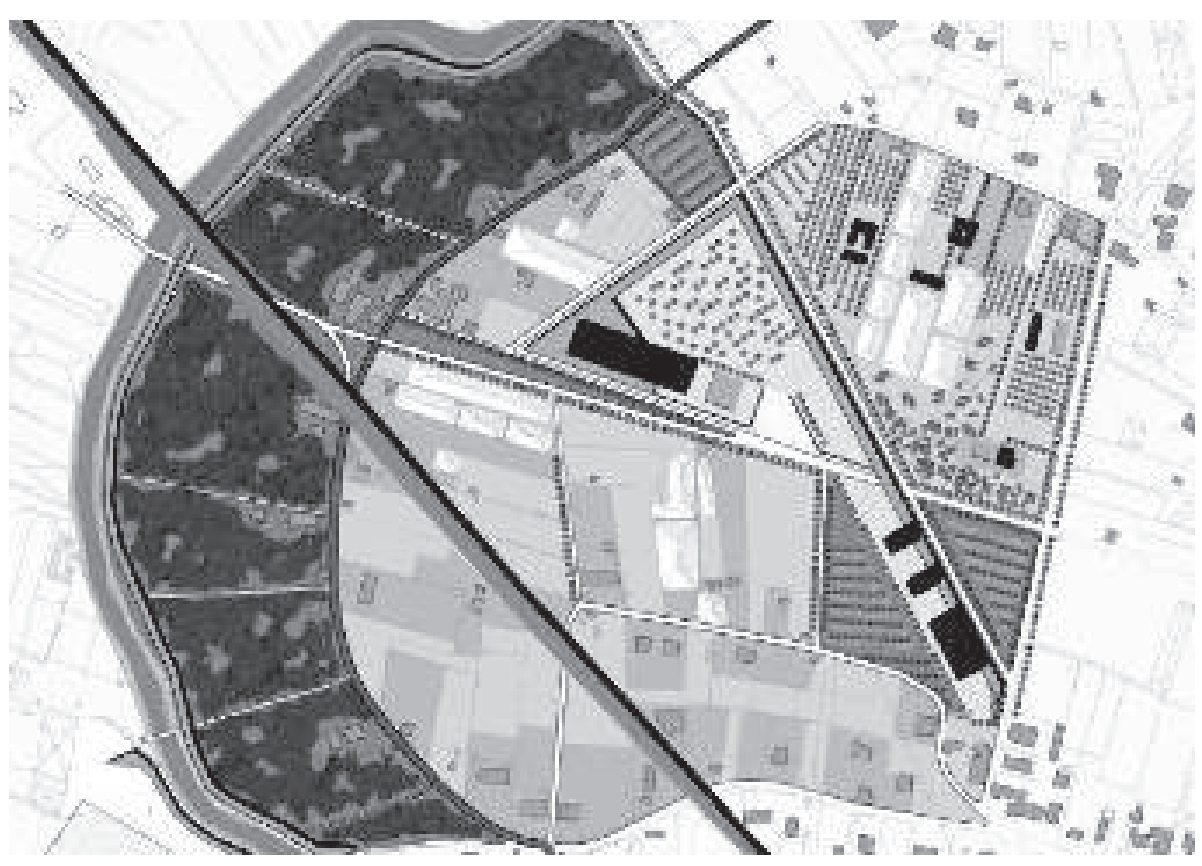

Figure 8: 4. Nature and Archaeology 
an elevated wooden walkway with resting places, from which to resume the view of the river, whose banks are often covered by tall reeds (Fig. 6).

At the height of San Marzano sul Sarno, in an agricultural area located at the confluence of the Sarno with the Cavaiola canal and other small waterways, there is a 'Knot of Water.' The elevated road S.S. 268 is the main access, and pedestrian bridges are connected to the new crossing road. Here the prevailing theme is nature, green, and enhancement of agricultural production, with large preserved farmland, and extensive areas of gardens and reforestation (especially towards the river). Here is located a "South Eataly" (market and restaurants $\mathrm{km}$. 0) such as a large greenhouse into a garden. Then there is a scattered hotel building with small residential structures in the countryside, some cubes placed in a little regular pattern of new canals; and finally, there is the same elevated wooden walkway, as a mark of constant relationship with the river (Fig. 7).

At last, there is the center 'Nature and Archaeology', close to San Valentino Torio, in a wide bend of the river with crops and greenhouses, close to recent findings of ancient pile-dwellings. So, it was decided to locate in this area a system of public places with a small archaeological museum that collects the finds, with guest quarters and workshops, and a center for training for River Park employees and other local needs. There are also educational farms, still reforestation areas along the river and the wooden walkway along the shore, connected to the archaeological site with small pedestrian bridges (Fig. 8).

\section{REFERENCES}

[1] Bollettino Regione Campania (2004) 27-5-2004, Parco naturale del Fiume Sarno

[2] BUSSI, R., Ed. (1984) Misurare la terra: centuriazione e coloni nel mondo romano, Edizioni Panini, Modena.

[3] CHOUQUER, G. et al. (1987), Structures agrarie en Italia centro-meridionale, ed. Ecole francaise de Rome,

[4] COPPA M. (1968), Storia dell'urbanistica. Dalle origini all'ellenismo, Einaudi Torino

[5] DE MATTEIS G. (1996), Progetto implicito, Franco Angeli, Milano

[6] DE SOLÀ MORALES M.(1999), Progettare città, Quaderni di Lotus 23, Milano

[7] GREGOTTI V.(2008), Il territorio dell'architettura, Feltrinelli, Milano

[8] HILBERSEIMER L. (1949), The new regional pattern, P. Theobald ed., Chicago

[9] MUSI P.(2003), Metonimie. La terra del Sarno, ed. Patto dell'Agro

[10] PESCE A., MILONE A, (2006), Una storia scritta sull'acqua, Massa ed., Napoli

[11] RENNA A.(1980), Le illusioni e i cristalli, CLEAR ed., Roma, p.68 e 72
Geographical

Structures and

Urban-Rural

Settlements: A

Design for the

Sarno River and its

Plain 